\title{
A COMPARISON OF THE EFFECTS OF HIGH AND LOW VISCOSITY GELATINS AFTER THEIR INTRAVENOUS INJECTION IN MAN ${ }^{1}$
}

\author{
By A. LOWELL, H. COLCHER, F. E. KENDALL, A. J. PATEK, JR., AND D. SEEGAL \\ (From the Research Service, First (Columbia) Division, Goldwater Memorial Hospital, \\ Department of Hospitals, and the College of Physicians and Surgeons, \\ Columbia University, New York City)
}

(Received for publication October 15, 1945)

The need for a substitute for plasma in the treatment of shock in the past few years has resulted in renewed interest in the use of gelatin solutions for intravenous injection. Many investigators have shown that intravenous injections of specially prepared gelatin solutions are well tolerated by man ( 1 to 6 ).

Gelatin is not a well defined chemical substance and its properties depend both upon the source material and the degree of molecular degradation during preparation. Studies at the Department of Physical Chemistry, Harvard Medical School, under the direction of Dr. E. J. Cohn (7) show that different lots of gelatin are best characterized by oncotic pressure, viscosity, and sedimentation pattern in the ultracentrifuge. In general, the least degraded products show the highest viscosity and the sharpest sedimentation pattern.

The purpose of the present study was to compare the effects produced in man by the intravenous injection of two gelatin solutions that differed greatly in their physical properties. Each patient received at different times comparable amounts of a high viscosity and a low viscosity gelatin preparation.

\section{MATERIALS AND METHODS}

Both preparations used in this study were ossein gelatin, and known to be pyrogen free. Low viscosity gelatin (LVG) was supplied by the Upjohn Gelatin Company, Kalamazoo, Michigan. This preparation, lot No. B20610 27, was a 4.5 per cent solution in isotonic saline and contained the preservative phenyl mercuric borate $1: 25,000$. The oncotic pressure was $70 \mathrm{~mm}$. of mercury and the relative viscosity was 2.9 at $55^{\circ}$ C. (7). This solution was fluid at room temperature.

High viscosity gelation (HVG) was supplied by the Knox Gelatin Company, Camden, New Jersey. The lot

1 The work described in this paper was done under a contract; recommended by the Committee on Medical Research, between the Office of Scientific Research and Development and Columbia University. used, No. $\mathrm{P7}-20$, was a 5.2 per cent preparation in isotonic saline containing the preservative phenyl mercuric borate 1: 40,000. The oncotic pressure was $55.6 \mathrm{~mm}$. of mercury and the relative viscosity was 5.81 at $55^{\circ} \mathrm{C}$. (7). This solution was a firm gel at room temperature and required heating to body temperature before injection. The ultracentrifuge patterns of both preparations furnished by J. L. Oncley are reproduced at the top of Figures 8 and 9.

The 11 patients studied were males. Their ages ranged from 21 to 72 years with 9 of the 11 over 50 years of age. All had been in the Goldwater Memorial Hospital for several years where they were being treated for such chronic diseases as rheumatoid arthritis, hemiplegia, Laennec's cirrhosis, chronic glomerulonephritis, melenosarcoma and thromboangiitis obliterans. None of these patients had shown signs of cardiac insufficiency.

Detailed studies of each patient were made throughout a control period of one week, the day of injection and a follow-up period of one week. Throughout this time each patient was kept in a private room and was maintained on a standard 3000 calorie diet containing 60 grams of protein. A careful record of fluid intake and output was kept although no restrictions were placed upon the fluid intake. Repeated clinical observations were made before, during and after injection of each of the gelatin preparations. Laboratory studies made during the control and follow-up periods included $x$-ray of the chest, electrocardiogram, complete blood count, erythrocyte sedimentation rate (8), prothrombin time (9), venous blood clotting time, bromsulphalein dye test (10), cephalin flocculation test (11), serum protein concentration and protein partition, non-protein nitrogen in blood and urine, urinalysis, urea clearance test (12), 24-hour urine albumin and total urea nitrogen in urine. All nitrogen determinations were done by the micro-Kjeldahl method. Serum levels and urinary excretion of gelatin were measured at suitable intervals following injection. Serum gelatin was determined by differential precipitation with trichloroacetic and tungstic acid and correction made for the presence of albumin (13). Concentrations of gelatin in serum and urine were calculated by multiplying their respective nitrogen values by the conversion factor $\mathbf{5 . 2 5}$.

\section{PROCEDURE}

Control data were obtained during a period of one week preceding the injection. On the day of injection the patients were given their usual breakfast. Blood samples 


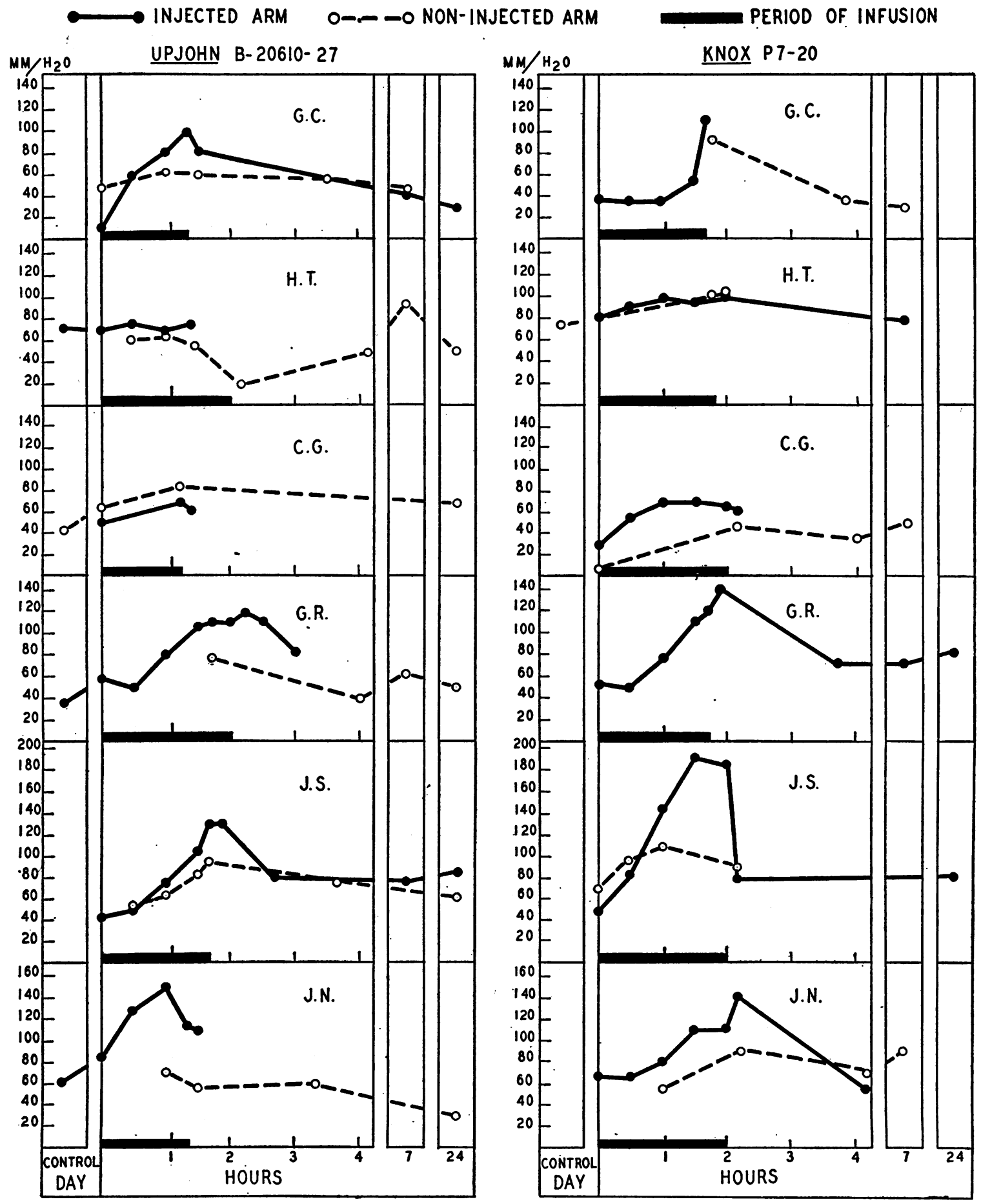

Fig. 1. Comparison of Two Gelatin Preparations

Venous pressure changes in injected and non-injected arms during and after infusion. 
TABLE I

Average concentration of gelatin in serum after infusion of $1000 \mathrm{ml}$. (10 patients)

\begin{tabular}{|c|c|c|c|c|c|c|}
\hline Time: & $10 \mathrm{~min}$. & 2 hrs. & 5 hrs. & 24 hrs. & $48 \mathrm{hrs.}$ & 72 hrs. \\
\hline $\begin{array}{l}\text { Low Viscosity Gelatin* } \\
\text { High Viscosity Gelatin }\end{array}$ & $\begin{array}{c}\text { grams per cent } \\
0.69 \\
0.99\end{array}$ & $\begin{array}{c}\text { grams per cent } \\
0.46 \\
0.89\end{array}$ & $\begin{array}{c}\text { grams per cent } \\
0.38 \\
0.79\end{array}$ & $\begin{array}{c}\text { grams per cent } \\
0.14 \\
0.51\end{array}$ & $\begin{array}{c}\text { grams per cent } \\
0.00 \\
0.32\end{array}$ & $\begin{array}{c}\text { grams per cent } \\
0.00 \\
0.13\end{array}$ \\
\hline
\end{tabular}

* Low viscosity gelatin (LVG) Upjohn B-20610-27, 4.5 per cent.

$\dagger$ High viscosity gelatin (HVG) Knox P7-20, 5.2 per cent.

$\longrightarrow$ KNOX P7-20
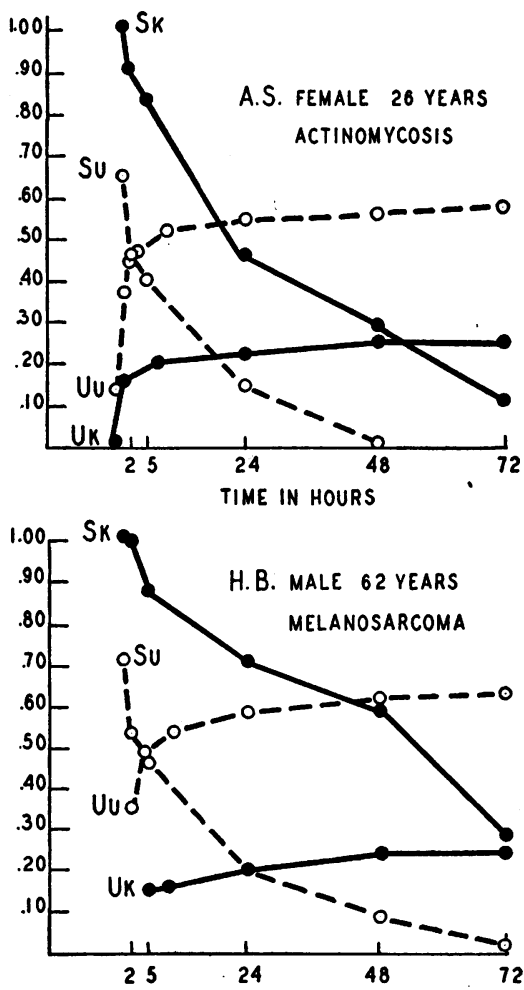

$0-\sim \rightarrow$ UPJOHN B-20610-27
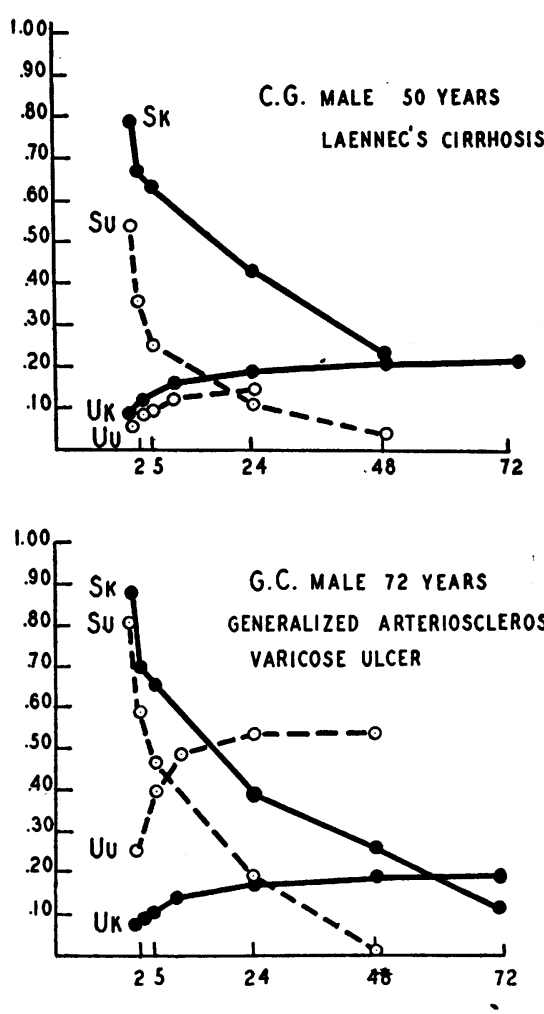

Fig. 2. Comparison of Two Gelatin Preparations

Serum levels and urinary excretion after intravenous injection in patients. Curves Sk and $\mathrm{Su}=$ serum gelatin in grams per cent. Curves $\mathrm{Uu}$ and $\mathrm{Uk}=$ cumulative fraction of gelatin recovered in urine. Note: Each patient received both gelatin preparations. Knox P7-20 and Upjohn B20610-27. An interval of at least 3 weeks elapsed between tests With one exception (Case G. C.) each infusion was $1000 \mathrm{ml}$. In the Knox preparation this corresponded to 52 grams of gelatin whereas it corresponded to 44.5 grams in the Upjohn preparation. The Knox preparation showed a slower disappearance from the blood stream and a lesser urinary excretion than the Upjohn preparation.

were taken for additional control determinations and venous pressure readings were obtained. One liter of the gelatin solution was then administered intravenously by gravity at the average rate of $10 \mathrm{ml}$. per minute. The HVG (high viscosity gelatin) was heated in a water bath at $37^{\circ}$ for about 30 minutes prior to its administration. The LVG (low viscosity gelatin) needed no such preliminary heating. Clinical observations comprising temperature, pulse and respiratory rates, blood pressure, auscultation of the chest and palpation for the liver and spleen were made during the injection and for 5 hours thereafter at 30 -minute intervals. Whenever possible, venous pressure readings were taken simultaneously in both arms at 30 -minute intervals during the injection Blood samples were obtained and additional venous pressure readings taken at 10 minutes, 2 hours, and 5 hours after completion of the injection. Urine specimens were collected as voided during and up to 5 hours post- 
injection. Thereafter, pooled specimens were collected over 4- and 12-hour periods. Daily blood samples and 24-hour urine specimens were taken for one week. At the end of this post-injection period, patients were returned to the ward where they remained for at least two weeks before receiving a second gelatin infusion. The order in which the preparations were given was purposely reversed in about one-half of the patients.
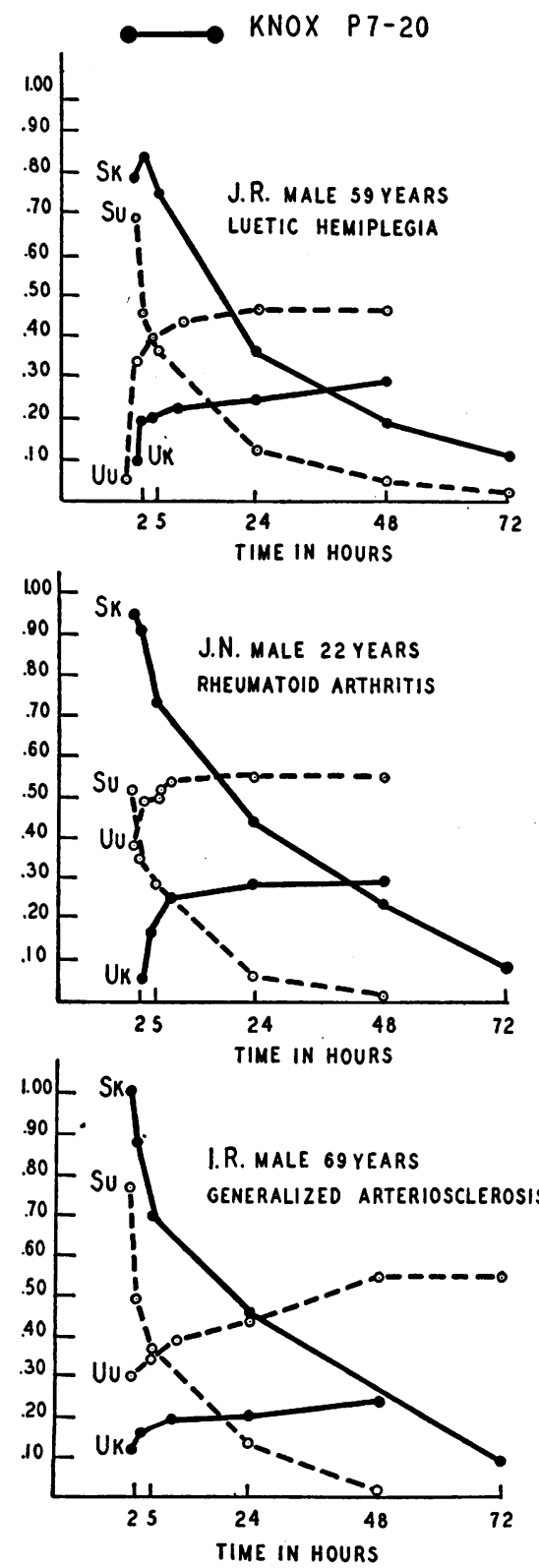

CLINICAL RESULTS

The infusion of either gelatin solution was generally well tolerated. No significant changes in temperature, pulse, respiration or blood pressure occurred during or after the administration of either preparation. In 3 patients who had previous signs of myocardial damage shown by elec-
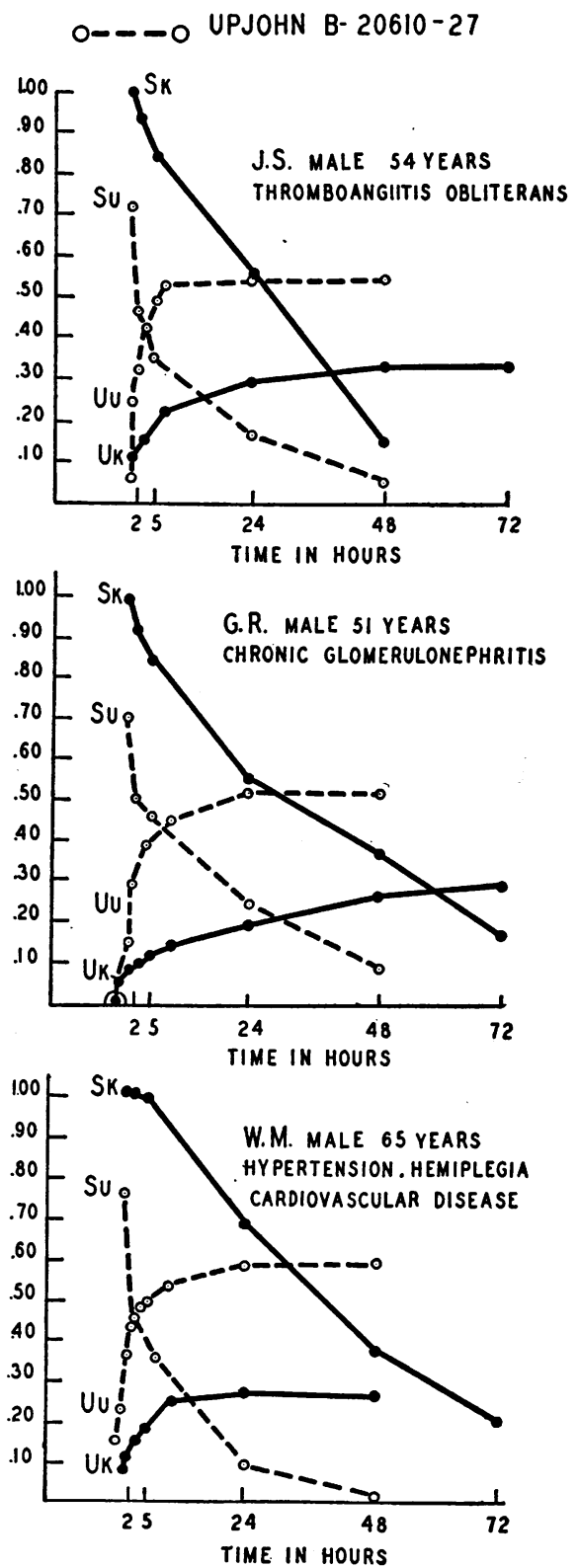

Fig. 3. Comparison of Two Gelatin Preparations

Serum levels and urinary excretion after intravenous injection in patients. Curves Sk and $\mathrm{Su}=$ serum gelatin in grams per cent. Curves $U \mathfrak{u}$ and $U \mathbf{k}=$ cumulative fraction of gelatin recovered in urine. 
trocardiogram, transient râles were heard at the lung bases. Five minor febrile reactions (3 with chill) followed infusion with HVG. It is our impression that these reactions were due to inadequate washing of the infusion tubing for none occurred after a change was made in the technique of washing the infusion set. In 3 patients ( 2 receiving $L V G$ and 1 receiving $H V G$ ) the injection caused pain which radiated up the arm.

During the course of this study 24 different veins were used for the injection of gelatin. Of these 13 became thrombosed within 24 hours, the veins becoming hard and cord-like. There were no associated systemic reactions and the thrombosed veins with 3 exceptions were painless and non-tender. Thrombosis extended upwards from the site of injection for distances of from 3 to 23 centimeters. Eight occurred after injection with LVG and 5 after injection with HVG. Investigation showed that this reaction was probably due

TABLE II

Rate of disappearance of the two gelatin preparations as determined by the constants of the equation, Log conc. $=A-B t$

\begin{tabular}{|c|c|c|c|c|c|c|}
\hline Patient & $\begin{array}{c}\text { Type } \\
\text { of } \\
\text { gelatin }\end{array}$ & A & B & $\begin{array}{c}\text { Max. diff. } \\
\text { between } \\
\text { exp't and } \\
\text { calc. } \\
\text { values }\end{array}$ & $\begin{array}{c}\text { Half } \\
\text { life } \\
\text { time }\end{array}$ & $\begin{array}{c}\text { Ratio } \\
\text { between } \\
\text { rates of } \\
\text { disappear- } \\
\text { ance }\end{array}$ \\
\hline & & & & $\begin{array}{l}\text { grams } \\
\text { per cent }\end{array}$ & days & $L V G / H V G$ \\
\hline H. B. & $\begin{array}{l}\text { LVG } \\
\text { HVG }\end{array}$ & $\begin{array}{r}-0.13 \\
+0.04\end{array}$ & $\begin{array}{l}0.44 \\
0.14\end{array}$ & $\begin{array}{l}0.11 \\
0.12\end{array}$ & $\begin{array}{l}0.68 \\
2.15\end{array}$ & 3.1 \\
\hline G. $R$. & $\begin{array}{l}\text { LVG } \\
\text { HVG }\end{array}$ & $\begin{array}{l}-0.19 \\
-0.01\end{array}$ & $\begin{array}{l}0.45 \\
0.22\end{array}$ & $\begin{array}{l}0.07 \\
0.05\end{array}$ & $\begin{array}{l}0.67 \\
1.37\end{array}$ & 2.1 \\
\hline J. R. & $\begin{array}{l}\text { LVG } \\
\text { HVG }\end{array}$ & $\begin{array}{l}-0.21 \\
-0.06\end{array}$ & $\begin{array}{l}0.75 \\
0.35\end{array}$ & $\begin{array}{l}0.11 \\
0.07\end{array}$ & $\begin{array}{l}0.40 \\
0.86\end{array}$ & 2.1 \\
\hline J. N. & $\begin{array}{l}\text { LVG } \\
\text { HVG }\end{array}$ & $\begin{array}{l}-0.33 \\
-0.03\end{array}$ & $\begin{array}{l}0.85 \\
0.31\end{array}$ & $\begin{array}{l}0.11 \\
0.05\end{array}$ & $\begin{array}{l}0.35 \\
0.97\end{array}$ & 2.7 \\
\hline G. C. & $\begin{array}{l}\text { LVG } \\
\text { HVG }\end{array}$ & $\begin{array}{l}-0.10 \\
-0.10\end{array}$ & $\begin{array}{l}0.69 \\
0.26\end{array}$ & $\begin{array}{l}0.10 \\
0.06\end{array}$ & $\begin{array}{l}0.44 \\
1.16\end{array}$ & 2.7 \\
\hline W. M. & $\begin{array}{l}\text { LVG } \\
\text { HVG }\end{array}$ & $\begin{array}{l}-0.21 \\
+0.08\end{array}$ & $\begin{array}{l}0.84 \\
0.24\end{array}$ & $\begin{array}{l}0.20 \\
0.03\end{array}$ & $\begin{array}{l}0.36 \\
1.25\end{array}$ & 3.5 \\
\hline J. S. & $\begin{array}{l}\text { LVG } \\
\text { HVG }\end{array}$ & $\begin{array}{r}-0.24 \\
0.00\end{array}$ & $\begin{array}{l}0.56 \\
0.25\end{array}$ & $\begin{array}{l}0.17 \\
0.03\end{array}$ & $\begin{array}{l}0.54 \\
1.20\end{array}$ & 2.4 \\
\hline C. G. & $\begin{array}{l}\text { LVG } \\
\text { HVG }\end{array}$ & $\begin{array}{l}-0.37 \\
-0.13\end{array}$ & $\begin{array}{l}0.52 \\
0.26\end{array}$ & $\begin{array}{l}0.13 \\
0.05\end{array}$ & $\begin{array}{l}0.58 \\
1.16\end{array}$ & 2.0 \\
\hline A. $S$. & $\begin{array}{l}\text { LVG } \\
\text { HVG }\end{array}$ & $\begin{array}{r}-0.23 \\
0.00\end{array}$ & $\begin{array}{l}0.61 \\
0.27\end{array}$ & $\begin{array}{l}0.09 \\
0.12\end{array}$ & $\begin{array}{l}0.49 \\
1.11\end{array}$ & 2.3 \\
\hline I. $R$. & $\begin{array}{l}\text { LVG } \\
\text { HVG }\end{array}$ & $\begin{array}{l}-0.14 \\
-0.02\end{array}$ & $\begin{array}{l}0.84 \\
0.30\end{array}$ & $\begin{array}{l}0.12 \\
0.12\end{array}$ & $\begin{array}{l}0.36 \\
1.00\end{array}$ & 2.8 \\
\hline
\end{tabular}

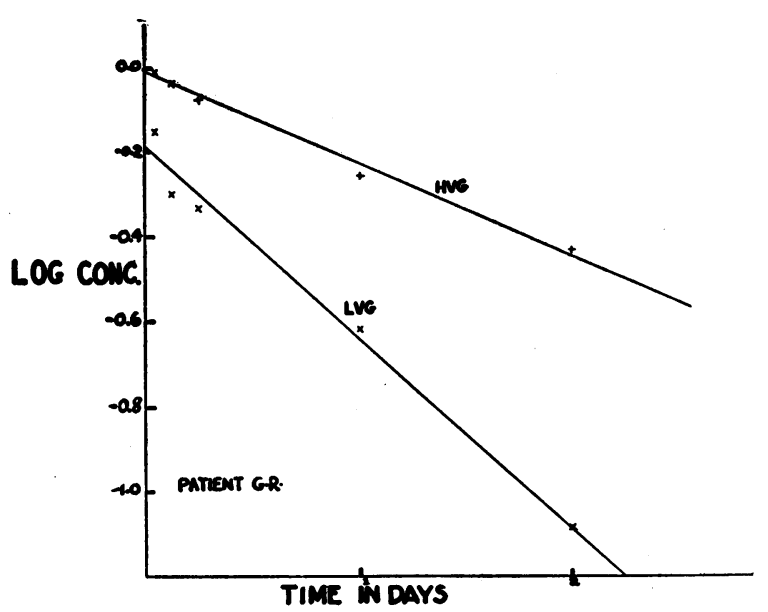

Fig. 4. Relationship Between the Log of Serum Gelatin Level and Time

chiefly to the mercurial preservative. These data are to be presented in a separate communication (14).

During 12 of 20 infusions there was a significant increase in venous pressure in the injected vein ranging from 20 to $115 \mathrm{~mm}$. of water. In 16 instances where simultaneous readings were made in the non-injected arm, only 4 showed an increase ranging from 40 to $75 \mathrm{~mm}$. of water. These changes which subsided within 2 hours apparently bore no relation to the type of gelatin injected. Figure 1 shows venous pressure readings in the injected and non-injected arms of 6 patients.

\section{LABORATORY RESULTS}

The average concentration of the 2 gelatin preparations in the serum are shown in Table I.

The data show that the initial serum level of HVG (Knox) was higher than that of LVG (Upjohn) and its rate of disappearance slower. At 24 hours there were still $510 \mathrm{mgm}$. per $100 \mathrm{ml}$. of the former in the serum, as compared to $140 \mathrm{mgm}$. per $100 \mathrm{ml}$. of the latter (Figures 2 and 3). Approximately 50 per cent of the LVG was recovered from the urine within 5 hours of injection, and a total of 55 per cent in 24 hours. In contrast, only 20 per cent of the HVG was recovered in 5 hours, and a total of 30 per cent in 24 hours.

In spite of the non-homogeneous nature of the gelatin preparations, they both obey the law of logarithmic disappearance from the serum over a 2-day period. If the logarithms of the serum 
gelatin concentrations are plotted against time, the points fall close to a straight line (Figure 4). Although this treatment is strictly empirical, it offers a convenient way of summarizing the data. By drawing the best straight line through the points, the effect of experimental error is minimized and the average rate of disappearance of each gelatin preparation over a period of 2 days can be obtained.

The equation of this line is: $\log$ conc. $=\mathrm{A}$ $-\mathrm{Bt}$, where " $\mathrm{t}$ " is time in days measured from the mid-point of the injection. " $A$ " represents the calculated gelatin concentration at zero time and " $B$ " the relative rate of disappearance of the gelatin. Table II gives the values for A and B for both preparations, the maximum deviation of the experimental values from the values calculated by the equation, the time required for half of the gelatin to disappear and the ratio between the rate of disappearance of the two preparations for each patient. The maximum difference found between the experimental values and the values cal- culated from the best straight line is less than twice the experimental error involved in the serum gelatin determinations. It will be seen from the table that the low viscosity gelatin disappears much faster than the high viscosity gelatin. The concentration of LVG in the serum can be expected to decrease by half in 0.49 ( $\sigma 0.12$ ) days and that of HVG in 1.23 ( $\sigma 0.11$ ) days.

No changes in the red blood cell, white blood cell and differential counts were observed after infusion with either preparation. The effects upon the erythrocyte sedimentation rate are shown in Figure 5. It will be noted that the rate usually increased sharply during infusion but fell to the control value within 24 to 48 hours. In the majority of instances, hemoglobin and hematocrit levels showed decreases of about 10 per cent 10 minutes after the end of infusion with either gelatin preparation. Thereafter the levels rose slightly at 2 and again at 5 hours, reaching control values at 24 hours after infusion.

At 10 minutes, 2 hours, and 5 hours after in-

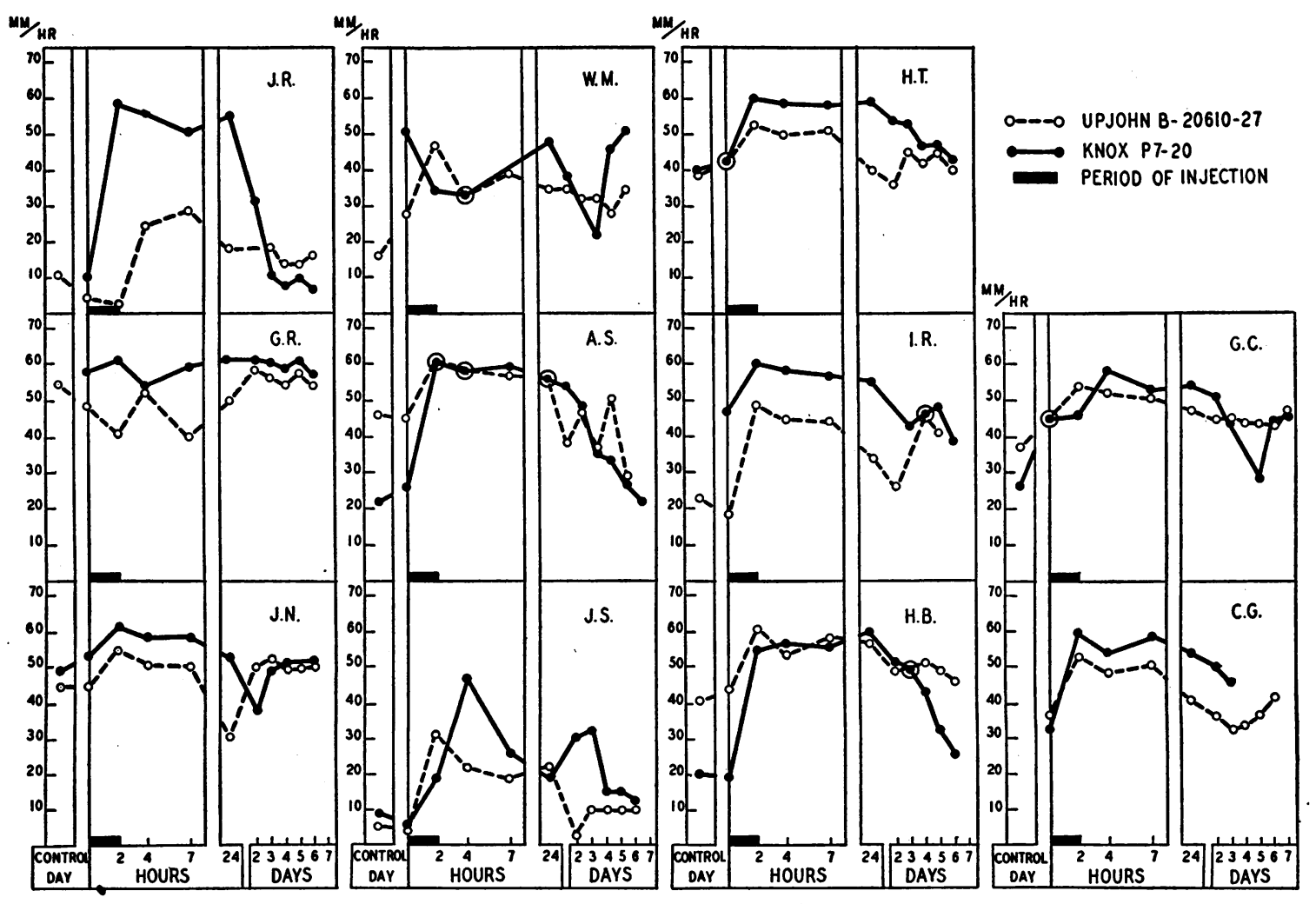

Fig. 5. Comparison of Two Gelatin Preparations

Changes in erythrocyte sedimentation rate after injection. 

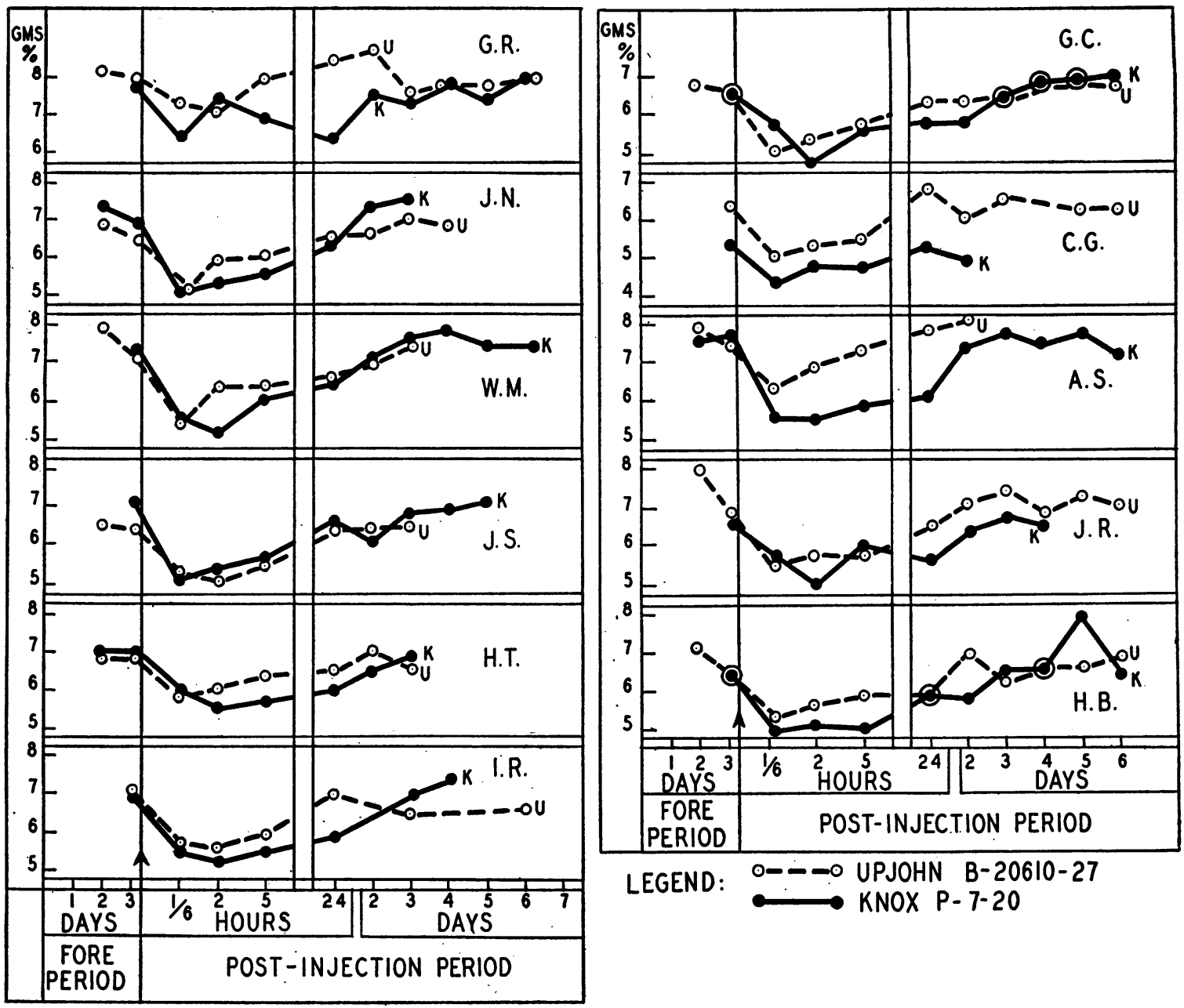

Fig. 6. Comparison of Two Gelatin Preparations

Changes in serum proteins after injection. Total serum proteins exclusive of gelatin.

fusion with LVG, the serum protein values showed a decrease but at 24 hours they had returned to initial levels. Somewhat more pronounced and protracted effects followed infusion with HVG. These changes are graphically represented in Figure 6.

Figure 7 shows levels of blood urea nitrogen and the daily urinary excretion of urea nitrogen preceding and following gelatin infusions. Occasionally a transient decrease of blood urea nitrogen occurred. Otherwise the infusions produced no significant changes in these values. No analyses for nitrogen in the stools were made.

Other tests pertaining to cardiac, hepatic and renal function showed no significant changes. However, a transient albuminuria lasting about
24 hours after the injection with either preparation was seen in most instances.

In Figures 8 and 9, we have attempted to compare graphically the changes in the majority of laboratory determinations with the time relationships which occurred in 2 representative cases following the intravenous administration of 1000 $\mathrm{ml}$. of each gelatin preparation. A brief history and a short discussion of these changes follows:

J. N., a 22-year-old, white, American-born man, entered the hospital in 1939 because of rheumatoid arthritis of 9 years' duration. Except for ankylosis and flexion deformities of the involved joints, there were no abnormal findings. Tests of cardiac, renal, and hepatic function were within normal limits. Laboratory tests showed no abnormalities other than an elevated sedimentation rate 
(45 to $50 \mathrm{~mm}$. per hour) and a $1+$ albuminuria determined by the sulphosalicylic acid method.

On $10 / 20 / 43$ patient was started on the special diet containing 60 grams of protein daily. On 11/4/43 he received $1000 \mathrm{ml}$. of LVG intravenously. No untoward reaction occurred. The following changes occurring after injection are shown in Figure 8: slight increase of sedimentation rate; rise of venous pressure in the injected vein but none in the opposite arm; transient decrease of hematocrit and serum protein; excretion of 50 per cent of the injected gelatin in 2 to 5 hours and 55 per cent in 24 hours; disappearance of detectable gelatin after 24 hours; little change in blood urea nitrogen or in urine urea nitrogen values.

On $12 / 9 / 43$ he received $1000 \mathrm{ml}$. of HVG intravenously. Four hours after the injection the patient had a chill with a temperature rise to 101.4. This reaction probably was not attributable to the gelatin solution ( $c f$. text p. 230). On the right hand side of Figure 7 'are shown the changes occurring after infusion with HVG. Though similar to those occurring after infusion with LVG, these changes are more pronounced and protracted. The HVG disappeared more slowly from the blood stream and was more slowly excreted in the urine. Only about 30 per cent of the injected gelatin was recovered from the urine in 48 hours.

In most respects this chart represents the changes seen in a group of 11 patients tested with these two gelatin preparations.

J. S., a 54-year-old Russian-born man with thromboangiitis obliterans of 11 years' duration, entered this hospital in 1939. Mid-thigh amputation of the right leg had been done in 1929 and of the left leg in 1937. Except for occasional epigastric distress, he had felt well. Examination showed mild cyanosis of the lips and fingertips, thickened radial blood vessels and mid-thigh amputations. Physical findings were otherwise normal. X-ray of the heart showed slight enlargement, the ECG's-left axis deviation. Blood pressure was $120 / 70$ bilaterally. Arteriography and oscillometry indicated impaired circulation in the hands. Laboratory tests showed no abnormalities other than a $1+$ albuminuria.

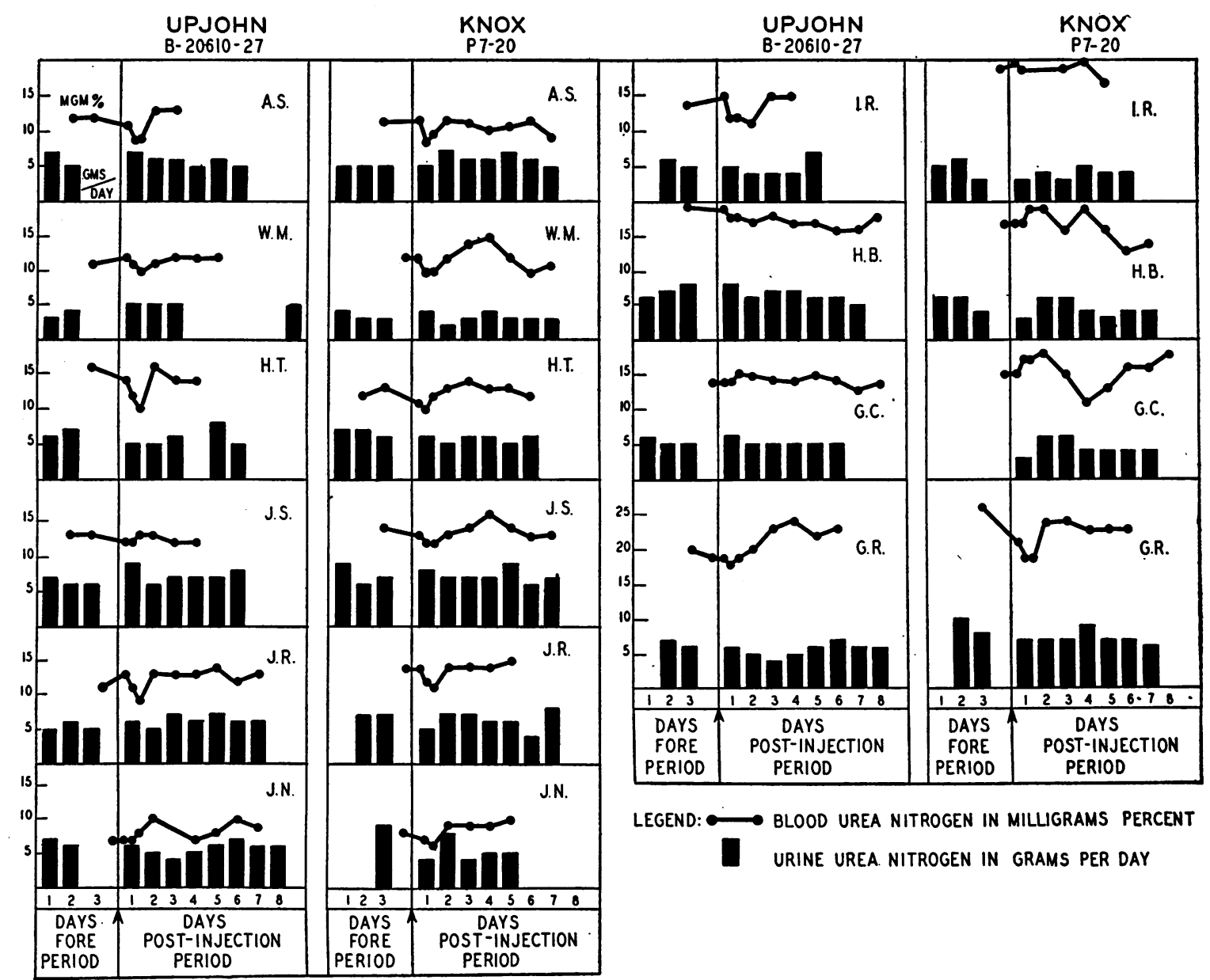

Fig. 7. Comparison of Two Gelatin Preparations

Changes in blood urea nitrogen and urine urea nitrogen after injection. 

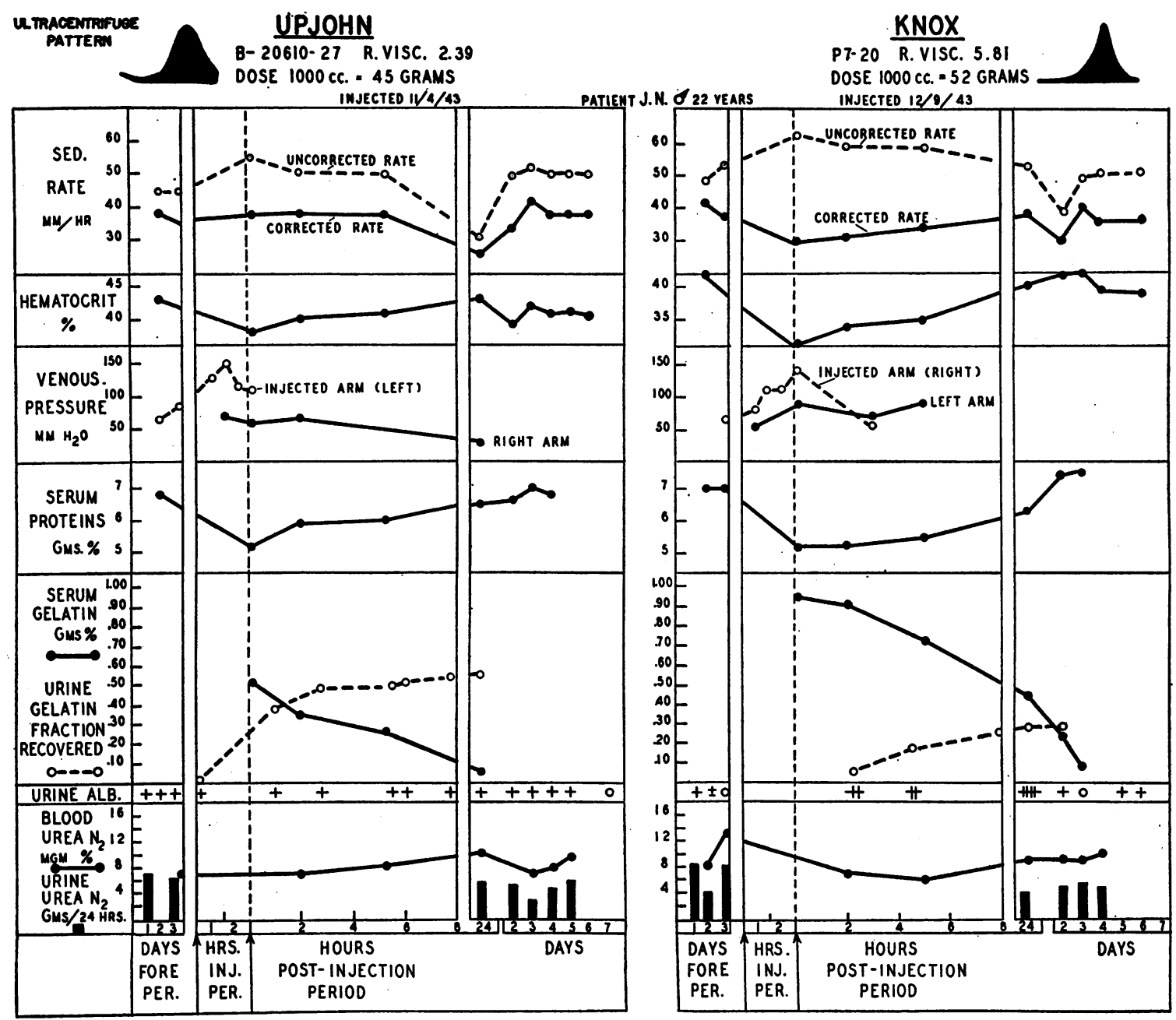

Fig. 8. Comparison of Effects of Two Gelatin Preparations

On $11 / 1 / 43$ the patient was started on the special diet containing 60 grams of protein daily. On 11/15/43 he received $1000 \mathrm{ml}$. of LVG. Intravenously no untoward reaction occurred. On 12/28/43 he received $1000 \mathrm{ml}$. of HVG. Changes after injections of both solutions are shown in Figure 6. The pattern of response to the 2 gelatin solutions is similar in both subjects although the effects are somewhat more pronounced and protracted after injection with $\mathrm{HVG}$.

On the day after injection with HVG, the vein was found to be thrombosed for a distance of $15 \mathrm{~cm}$. from the site of injection. This reaction, observed in other patients, has been discussed in the text ( $c f$. p. 230).

\section{DISCUSSION}

Since every patient received $1000 \mathrm{ml}$. of each of the two gelatin preparations, a comparison of their effects in the same patient was made possible.
Our experience with these two gelatin preparations confirms previous observations that the intravenous injection of such solutions is generally well tolerated ( 1 to 6 ). With the exception of a few minor febrile reactions already referred to, there were no untoward effects. This finding was further substantiated by a subsequent series of about 40 injections given to patients in another investigation.

The frequent occurrence of thrombosis in the injected vein, although without serious sequelae, presented a local obstacle to repeated infusions. Our experience in this regard is in contrast to that of Koop et al. (4) who found venous thrombosis to occur less frequently with gelatin than with plasma. Further investigation showed that 
this reaction could be avoided by using a gelatin solution containing no preservative.

With regard to venous pressure changes, it was felt that the finding of a rise in the injected vein did not necessarily reflect a rise in the rest of the venous system. Simultaneous measurements in the opposite arm showed only slight venous pressure changes in the majority of instances. Both preparations elicited similar responses.

After injection with HVG the serum gelatin reached a higher initial concentration and disappeared more slowly from the blood stream than after injection with LVG. Likewise the rate of excretion of gelatin in the urine was much slower in the case of HVG. Account should be taken of the fact that the quantity of HVG injected was 15 per cent greater than that of LVG. However, the average initial serum level after infusion with HVG was 27 per cent greater than the average initial level after LVG.

The transient albuminuria during the first 24 hours after infusion accounted for the appearance of from 10 to 15 grams of protein in the urine. It is of interest that after correction for this albumin, the recovery of gelatin in the urine never exceeded 50 per cent of the amount of LVG injected nor 30 per cent of the amount of $\mathrm{HVG}$ injected. Other investigators, using similar though not identical preparations, have reported the recovery of larger amounts of gelatin in the urine (6). No information is available with regard to the unrecovered gelatin.

The changes in hemoglobin, hematocrit and serum protein values reflect a certain degree of
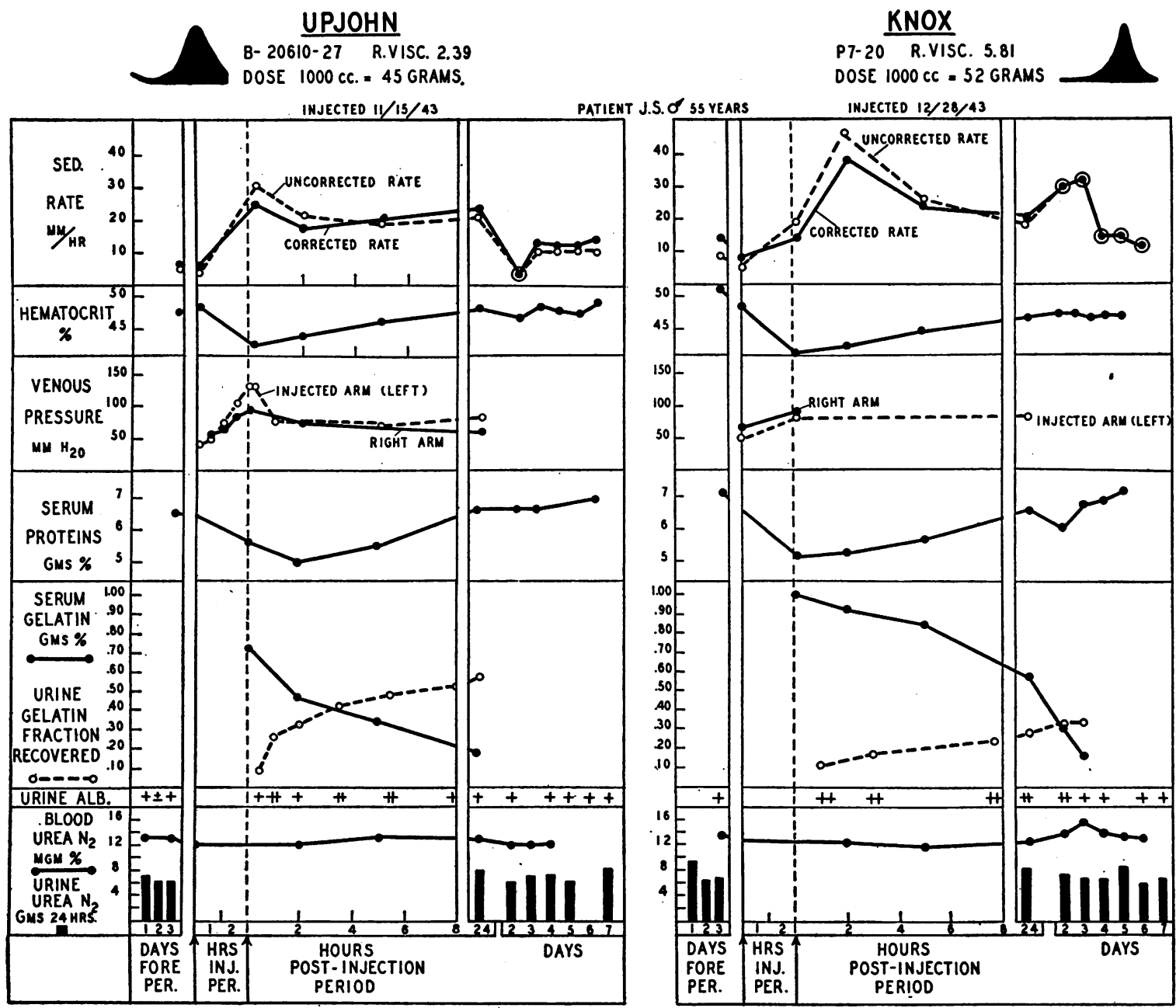

Fig. 9. Comparison of Effects of Two Gelatin Preparations 
hemodilution. An accurate gauging of this phenomenon, however, cannot be made in the absence of plasma volume studies.

A sharp increase in the erythrocyte sedimentation rate seen during and following the infusion of each preparation was also produced in vitro by adding gelatin to the whole blood. This seems to be due to the effect of large sized asymmetrical molecules upon the erythrocytes (15).

The results obtained with HVG are consistent with those described in a recent study on the use of a similar high viscosity gelatin as a plasma substitute (16).

\section{CONCLUSIONS}

1. The infusion of either high viscosity gelatin or low viscosity gelatin was generally well tolerated.

2. High viscosity gelatin reached a higher initial serum concentration, was retained longer in the blood stream and was excreted more slowly in the urine than low viscosity gelatin.

3. The fall in hemoglobin, hematocrit and serum protein values suggesting hemodilution were more pronounced after the intravenous administration of high viscosity gelatin.

4. There was a marked rise in erythrocyte sedimentation rate with each preparation. This returned to control levels within 24 to 48 hours.

5. A transient rise in venous pressure occurred frequently in the injected vein whereas simultaneous measurements in the opposite arm showed a less marked rise or no rise at all.

6. Thrombosis of the injected vein was a common sequel to the infusion of either preparation containing the preservative phenyl mercuric borate. When gelatin preparations without preservative were tested, the incidence of thrombosis declined sharply.

7. Tests pertaining to cardiac, hepatic, and renal function showed no significant changes except for a transient albuminuria seen in most cases and lasting about 24 hours.

The work described in this paper was carried out with the technical assistance of Liese Lewis, Velma Brewington, Anne Colcher, Beatrice Domanski, Grace Kirschenbaum, and Walter Meyer.

\section{BIBLIOGRAPHY}

1. Hogan, J. J., The intravenous use of colloidal (gelatin) solutions in shock. J. A. M. A., 1915, 64, 271.

2. Amberson, W. R., Blood substitutes. Biol. Rev., 1937, $12,48$.

3. Parkins, W. M., Koop, C. E., Riegel, C., Vars, H. M., and Lockwood, J. S., Gelatin as a plasma substitute with particular reference to experimental hemorrhage and burn shock. Ann. Surg., 1943, 118, 193.

4. Koop, C. E., Fletcher, A. G., Jr., Riegel, C., and Lockwood, J. S., Gelatin as a plasma substitute: a preliminary report of clinical experience. Surgery, 1944, 15, 839.

5. Holt, J. L., and Knoefel, P. K., Changes in plasma volume and cardiac output following the intravenous injection of gelatin, serum, and physiological saline solution. J. Clin. Invest., 1944, 23, 657.

6. Jacobson, S. D., and Smyth, C. G., Gelatin as a substitute for plasma. Observations on its administration to human beings. Arch. Int. Med., 1944, 74, 254.

7. Scatchard, G., Oncley, J. L., Williams, J. W., and Brown, A., Size distribution in gelatin solutions. Preliminary report. J. Am. Chem. Soc., 1944, 66, 1980 , and personal communication.

8. Wintrobe, M. M., and Landsberg, A standard technique for the blood sedimentation test. Am. J. M. Sc., 1935, 189, 102.

9. Quick, A. J., The clinical application of the hippuric acid and the prothrombin tests. Am. J. Clin. Path., 1940, 10, 222.

10. O'Leary, P. A., Greene, C. H., and Rowntree, L. G., Diseases of the liver. VIII. The various types of syphilis of the liver with reference to tests for hepatic function. Arch. Int. Med., 1929, 44, 155.

11. Hanger, F. M., Flocculation of cephalin-cholesterol emulsions by pathological sera. Tr. A. Am. Physicians, 1938, 53, 148.

12. Van Slyke, D. D., Determination of urea by gasometric measurement of the carbon dioxide formed by the action of urease. J. Biol. Chem., 1927, 73, 695.

13. Little, J. M., and Wells, H. S., Capillary permeability to intravenously administered gelatin. Am. J. Physiol., 1943, 138, 495.

14. To be published.

15. Meyer, K., Hahnel, E., and Feiner, R., Experiments on erythrocyte sedimentation rate. Proc. Soc. Exper. Biol. and Med., 1945, 58, 36.

16. Fletcher, A. G., Jr., Hardy, J. D., Riegel, C., and Koop, C. E., Gelatin as a plasma substitute: the effects of intravenous infusion of gelatin on cardiac output and other aspects of the circulation of normal persons, of chronically ill patients, and of normal volunteers subjected to large hemorrhage. J. Clin. Invest., 1945, 24, 405. 